\title{
CoMuniCAÇÃo ESTRATÉGICA NO AMBIENTE COMUNICATIVO DAS ORGANIZAÇÕES ATUAIS
}

\author{
Maria Victoria Carrillo \\ vicduran@unex.es \\ Universidad de Extremadura (Espanha) Facultad de Ciencias de la Documentación \\ y la Comunicación Plaza Ibn Marwan s/n 06001 Badajoz. Espanha
}

\begin{abstract}
Resumo
Este artigo procura clarificar o conceito de comunicação estratégica enquanto componente dos novos desafios de comunicação com que se deparam, atualmente, as empresas, (Carrillo et al., 2013). A comunicação estratégica tornou-se uma área de trabalho académica e profissional de crucial importância. A delinear as questões subjacentes a esta área de trabalho teórico e profissional encontra-se um desafio para estudiosos das ciências da comunicação. Uma definição correta do conceito deverá responder à necessidade de incluir a comunicação nas competências essenciais da equipa de gestão sénior, bem como cumprir uma série de objetivos predefinidos, a longo prazo, concebidos tendo em vista a satisfação dos interesses de cada um dos stakeholders de uma empresa ou organização.
\end{abstract}

Palavras-chave

Comunicação; estratégia; organizações

\section{O PONTO DE PARTIDA DA COMUNICAÇÃo ESTRATÉGICA}

Há apenas alguns anos, quase ninguém falava de comunicação na empresa, no que diz respeito às suas funções individualizadas de gestão e de marketing. Atualmente, em diversas organizações estas duas funções encontram-se nitidamente separadas, e a comunicação organizacional é vista como tendo, em geral, um caráter estratégico que a levou a ocupar o lugar dominante nas posições de topo do organigrama. Esta situação transforma este aspeto estratégico num campo de estudo obrigatório nas ciências da comunicação e numa oportunidade de trabalho para futuros profissionais deste campo.

Autores como Pérez \& Massoni (2009) propõem uma panorâmica dos futuros profissionais da estratégia e fornecem algumas orientações tendo em vista a conceção e implementação de estratégias em diferentes áreas da vida: economia, política, sociedade, educação, cultura e comunicação. Porém, acreditamos que os atuais modelos estratégicos não se ajustam adequadamente aos novos contextos sociais e da comunicação. O presente artigo tem, assim, como objetivo abordar o conceito de comunicação estratégica como um novo tema emergente no campo da comunicação em geral, e da comunicação das organizações em particular.

Embora a comunicação estratégica não seja, na prática, realmente diferente daquilo que já vinha sendo feito, representa uma forma de compreender a comunicação distinta da forma como era tradicionalmente vista.

Geralmente, a comunicação estratégica como parte do universo de comunicações de uma organização é vista como estando muito próxima daquilo que se designou 
comunicação holística ou integral, ou seja, uma forma de unificar as diferentes ações de comunicação concebidas para ajudar a alcançar as metas estratégicas de uma empresa (Schultz et al., 1994).

Naturalmente, a comunicação não faz parte dos esforços encetados para alcançar as metas estratégicas da empresa, mas antes das metas que dependem ou necessitam de uma relação com os stakeholders de uma empresa, de modo a poder acrescentar valor. Este é, sobretudo, o caso da imagem e da reputação, através dos quais poderá concluir-se que a comunicação também contribui para alcançar as metas comerciais da empresa.

A diferença entre a comunicação holística ou integral e a comunicação estratégica reside apenas no facto de cada uma delas realçar um conceito diferente. Enquanto a comunicação holística ou integral baseia-se na inclusão de todas as ações possíveis (incluindo aquilo que tradicionalmente se designa por comunicação externa e interna) para alcançar as metas da empresa, a comunicação estratégica define-se mais na perspetiva das metas a alcançar e das decisões a adotar para o efeito do que numa perspetiva das ações a adotar. Naturalmente, estas decisões implicam a adoção de ações da comunicação holística ou integral, sendo esta, de facto, a relação que as liga.

Em termos genéricos, a comunicação estratégica não é nova. O papel desempenhado pela estratégia é uma condição indispensável à comunicação orientada para as metas, sendo ela própria obrigatória no contexto da comunicação das organizações, independentemente do tipo dessas comunicações.

Pérez (2001), um pioneiro na definição da estratégia no campo da comunicação, defende que a comunicação estratégica é um recurso essencial para uma empresa. Confessou, recentemente, o autor (2012: 8) que: "Para todos aqueles que, como eu, passaram anos a trabalhar nesta área, o aparecimento da comunicação estratégica é, indubitavelmente, uma boa notícia. Contudo, o êxito nunca surge sem contrapartidas, e constato a existência de algumas anomalias na forma como esta expressão está a ser tratada. Como se de um modismo se tratasse, alguns autores usam e abusam do termo". Por conseguinte, na literatura mais recente surgiram várias referências diretas ou indiretas à comunicação estratégica. Existem, atualmente, documentos que poderão contribuir, como refere Pérez (2012), com um maior ou menor grau de adequação, para o desenvolvimento de um corpus teórico e prático relativamente à definição de comunicação estratégica.

Scheinsohn \& Saroka (2000) referem que, no final dos anos 80 do século XX, iniciaram inadvertidamente o novo movimento que ficaria posteriormente conhecido como comunicação estratégica. Outros estudos terminaram a sua visão de comunicação estratégica e reforçaram a abordagem que os dois autores descreveram. Classificam a sua proposta como tendo sido provocativa porque: "Numa época em que o marketing estava a conquistar exponencialmente um certo 'vedetismo', defendia-se que as funções da comunicação ultrapassam as fronteiras do marketing, tendo-se, por isso, sugerido que a comunicação fosse implementada como parte da área da gestão de topo". Observam os autores que, embora seja verdade que a comunicação empresarial foi, durante muito tempo, considerada sinónimo de publicidade, esta atitude reducionista foi derrubada por autores como Shultz et al. (1994), que alertaram para a necessidade de integrar as diferentes técnicas modernas de comunicação no trabalho para alcançar as 
metas da organização. Nesta mesma linha, a comunicação estratégica não se limita ao campo dos produtos e das marcas (estas últimas vistas como extensões dos primeiros). A comunicação estratégica deve ser articulada de forma inteligente recorrendo a ações de gestão holística e, como o seu nome indica, colocada em prática através da aplicação de uma lógica eminentemente estratégica a partir da única área da empresa que permite fazê-lo: a da gestão sénior. Em suma, a comunicação estratégica inclui comunicação de marketing, mas não exclusivamente.

Para Garrido (2004), o cerne do conceito de estratégia no atual contexto da comunicação não deixa margem para qualquer solução de êxito junto dos modelos de comunicação tradicionais e da sua adesão aos princípios do passado. O autor refere-se ao reducionismo "marketiniano" como sendo um mero exercício de ações de comunicação isoladas.

Hallahan et al. (2007) baseiam, parcialmente, o seu estudo na opinião de um painel composto por editores de um jornal e por académicos da área da comunicação internacional para analisar a natureza do conceito de comunicação estratégica. Concluem que existem seis áreas nas organizações, e não apenas a do marketing, subjacentes ao desenvolvimento do conceito de comunicação estratégica: o próprio marketing, gestão de empresas, relações públicas, tecnologias da comunicação, políticas da comunicação e campanhas de marketing social ou informativo.

Islas (2005) afirma que duas das principais áreas nas quais a comunicação estratégica intervém são as da cultura e da identidade da organização. $O$ autor destaca a relação entre a comunicação estratégica e a gestão dos recursos intangíveis da empresa, afirmando: "O prestígio e a reputação de qualquer marca ou organização dependem, atualmente, menos do esforço publicitário e mais de uma abordagem integrada, que envolve necessariamente a comunicação estratégica".

Na sua discussão da comunicação estratégica, Tironi \& Carvallo (2011) realçam, ainda, o facto de, no mundo corporativo, as oportunidades atuais se encontrarem no campo da imagem, e não no da produção, o que contribui para sustentar ainda mais a função da comunicação estratégica como estando ao serviço da gestão de recursos intangíveis.

A tabela que se segue apresenta, em forma de síntese, as principais áreas abrangidas pela comunicação estratégica, com base no pressuposto fundamental de que é a forma de comunicação que está ao serviço do cumprimento das metas da organização.

\begin{tabular}{|c|c|}
\hline \multicolumn{2}{|c|}{ Áreas de comunicação estratégica } \\
\hline \multicolumn{2}{|c|}{ Comunicação estratégica $\rightarrow$ As metas da organização de acordo com os seus stakeholders } \\
\hline $\begin{array}{l}\text { Gestão de recursos intangíveis } \\
\text {-Imagem } \\
\text {-Reputação } \\
\text {-Marca como recurso intangível } \\
\text {-Identidade } \\
\text {-Cultura corporativa } \\
\text {-Responsabilidade social corporativa }\end{array}$ & $\begin{array}{l}\text { Imagem (Tironi \& Carvallo, 2011). } \\
\text { Identidade, cultura organizacional, reputação (Islas, 2005). } \\
\text { Gestão de empresas e campanhas de marke- } \\
\text { ting social (Hallahan et al., 2007). }\end{array}$ \\
\hline Comunicação empresarial & Políticas de comunicação e marketing (Hallahan et al., 2007). \\
\hline Comunicação externa & Relações públicas, políticas de comunicação (Hallahan et al., 2007). \\
\hline Comunicação interna & $\begin{array}{l}\text { Políticas de comunicação, tecnologias de comunicação } \\
\text { (Hallahan et al., 2007). }\end{array}$ \\
\hline
\end{tabular}

Tabela 1

Fonte: Os autores, com base em Hallahan et al., (2007), Tironi \& Carvallo (2011) e Islas (2005) 


\section{O CONCEITO DE ESTRATÉGIA E A SUA APLICAÇÃo À COMUNICAÇÃO}

Não é possível definir comunicação estratégica sem fazer referência ao próprio termo "estratégia". Este, por sua vez, é complementado por dois conceitos adicionais, que também interessa analisar: "tática" e "plano".

Embora todos acreditem compreender o significado de "estratégia", nem sempre sabem como definir o termo corretamente. Matilla (2007:17) admite que: "O conceito de estratégia é um termo definido com frequência de modo livre, ambíguo e, por vezes, confuso. E um termo que é utilizado abusivamente com frequência".

O termo estratégia, como parte do conceito de "pensamento estratégico", poderá ser visto como uma forma de combinar os objetivos a alcançar a longo prazo e as decisões a tomar antecipadamente, prevendo cenários futuros e possíveis ameaças do ambiente.

Para ser estratégica, uma decisão deve ter em consideração o modo como as reações de outras pessoas que tentam atingir os seus próprios objetivos têm potencial para influenciar o processo, bem como os efeitos de outros fatores relacionados com o ambiente, como o acaso.

Metaforicamente, a estratégia é o percurso que mapeia a priori e que, posteriormente, procura seguir, agindo de modo a que as suas decisões se ajustem aos objetivos definidos à partida. Assim, o primeiro passo na criação de uma estratégia consiste em saber para onde vai; não é lógico começar uma viagem sem saber qual é o destino. $O$ segundo passo consiste em coordenar as suas ações e os recursos disponíveis, procurando posicionar-se favoravelmente face aos seus concorrentes, ou seja, em escolher as opções adequadas ao percurso traçado, de modo a permitir-lhe chegar onde pretende mais rápida e eficientemente do que os seus concorrentes.

O conceito seguinte a clarificar é o de tática. A estratégia utiliza a tática que irá ajudar a definir a forma de atingir os objetivos. A tática é, assim, constituída por decisões que devem ser tomadas antecipadamente, ainda que possivelmente reorientadas e reformuladas ao longo do tempo.

Nesta fase, é essencial incluir o conceito de temporalidade no estudo e na definição de estratégia. A estratégia deve ser pensada a longo prazo. Não é possível delinear uma estratégia a curto prazo, uma vez que, neste caso, não haveria tempo para a desenvolver na forma de táticas. Argenti et al. (2005), por exemplo, explicam os motivos pelos quais as empresas que só tomam decisões relativamente à comunicação tática, a curto prazo, sem uma estratégia, têm dificuldade em competir.

Finalmente, a tática desenvolve-se ainda mais na forma de planos de ação. Estes são mais pragmáticos, devendo, por conseguinte, ser implementados num período de tempo ainda mais específico. Uma determinada tática pode conduzir ao desenvolvimento de um ou mais planos de ação, concebidos para serem executados consecutiva ou paralelamente no tempo, mas sempre orientados para o mesmo objetivo a longo prazo. Cada um dos planos pode possuir diferentes objetivos parciais, capazes de serem cumpridos a curto prazo.

Resumindo, a abordagem à comunicação estratégica descrita neste artigo, que diferencia a estratégia da tática e a tática dos planos de ação, segue a linha traçada 
por Scheinsohn \& Saroka (2000) segundo a qual a comunicação estratégica inclui os seguintes níveis de ação: estratégico, logístico, tático e técnico. Também estes autores discutem a estratégia como conceção de uma ação integradora que nos ajuda a ter uma perspetiva clara do ponto em que nos encontramos e do ponto para onde vamos. Aquilo que a define é o conhecimento dos objetivos a atingir. A estratégia concentra-se mais na exploração da força potencial da organização do que na acumulação e aplicação de recursos.

Diretamente relacionado com o nível estratégico, está o nível logístico. Este consiste em orientar a manutenção de todos os recursos necessários para alcançar os objetivos estratégicos. A logística fornece e distribui estes recursos.

O nível tático diz respeito a tudo aquilo que está relacionado com ações ou meios. A tática constitui a forma de otimizar a utilização de recursos e de identificar o momento certo para a sua implementação. Neste sentido, consideramos ferramentas de comunicação táticas todas as técnicas e meios aceites: publicidade, promoção, eventos, relações de informação com os média, planos de comunicação financeiros, preparação de um manual de identidade corporativa visual, etc.

Finalmente, o nível técnico corresponde a todas as decisões operacionais resultantes da tática. Este artigo, pelo contrário, recorre ao termo "planos de ação", que serão operacionalizados através de programas de intervenção. Um programa de intervenção consiste num conjunto de ações com uma maior estabilidade ao longo do tempo. Pode ser constituído, por exemplo, por uma única ação específica, como é o caso da realização de uma campanha publicitária. Enquanto uma campanha publicitária procura alcançar objetivos táticos, um programa possui objetivos estratégicos. A tática, porém, necessita de cumprir as metas definidas a curto prazo e contribuir para os objetivos estratégicos a longo prazo de uma forma sinergética, de modo a que o resultado da aplicação da tática determinada a priori seja mais do que apenas a soma dos resultados de cada um deles, isoladamente.

Não podemos esquecer que o objeto de estudo deste artigo é a estratégia na sua relação com a comunicação. Existem algumas diferenças entre a estratégia aplicada à comunicação e a estratégia aplicada a outras áreas da vida, como o contexto militar. Os recursos disponíveis para agir no campo da comunicação baseiam-se na troca de informações e mensagens, e não na interação física, como é o caso de situações de guerra, o que irá obrigar a empresa ou instituição a recorrer à comunicação estratégica para avaliar constantemente as suas relações com os seus stakeholders, de modo a assegurar que o estado dessas relações se adequa aos seus objetivos estratégicos, e a certificar-se de que as mensagens emitidas foram devidamente recebidas e descodificadas.

\section{A eSTRATÉgia No AMBIENTE DE COMUNiCAÇÃo DAS ORGANIZAÇÕeS}

Conforme discutido anteriormente, a estratégia desempenha um papel importante no contexto da gestão da comunicação. É necessário destacar algumas características importantes ao considerar a estratégia aplicada à comunicação das organizações. 
Em primeiro lugar, a comunicação estratégica deve ser uma comunicação gerida. Um aspeto importante consiste em compreender que a comunicação não pode ser estratégica se não for gerida. Gerir algo significa intervir, agir sobre os seus elementos para os alterar de modo a obter algum tipo de vantagem. Gerir a comunicação implica utilizar os recursos disponíveis para atingir determinado fim. Nesta perspetiva, poderia dizer-se que a comunicação gerida é comunicação estratégica? De todo. É necessário ter em conta uma pequena, mas importante nuance: a comunicação gerida nem sempre é comunicação estratégica, embora a comunicação estratégica seja sempre comunicação gerida.

Em segundo lugar, a "comunicação estratégica" não é sinónimo de "estratégias de comunicação". A comunicação estratégica necessita de recorrer a todas as formas de comunicação disponíveis para satisfazer os seus objetivos. Cada uma destas formas será delimitada pela sua própria tática e pelos seus próprios planos de ação, constituindo aquilo que é muitas vezes referido como "estratégias de comunicação" parciais. Daí a confusão. Será o somatório de todas as "estratégias de comunicação" parciais que dará origem à sinergia que nos permite falar de "comunicação estratégica". Decorrente da sinergia, o resultado da comunicação estratégica será muito mais do que a soma das "estratégias de comunicação" parciais que poderá incluir. Por exemplo, a publicidade não deverá ser considerada comunicação estratégica, antes pelo contrário; a comunicação estratégica inclui a publicidade e outras formas de comunicação para alcançar os seus objetivos a longo prazo. Assim, os objetivos parciais a alcançar com a "estratégia de comunicação publicitária" contribuem para a criação de valor e para a satisfação dos objetivos estratégicos definidos pela organização, mas não coincidem com estes, o que irá forçar a empresa a conhecer o peso relativo de cada forma de comunicação, de modo a estimar a possível rentabilidade de cada um deles. A empresa também será obrigada a procurar a coerência entre todas as "estratégias de comunicação parciais", com vista a uma leitura uniforme das ameaças, fraquezas, oportunidades e forças potenciais.

Em terceiro lugar, a comunicação estratégica encontra-se necessariamente ligada à organização: o termo comunicação estratégica não possui qualquer significado fora do contexto das organizações. O termo organização é, aqui, entendido como sendo a empresa ou instituição, pública ou privada, que trabalha de forma organizada, no mesmo sentido, para atingir determinado objetivo ou cumprir determinada missão e concretizar a sua visão estratégica, de cujo contexto participa. Nesta mesma linha, Hallahan et al. (2007) definem a comunicação estratégica como a comunicação feita deliberadamente por uma organização para cumprir a sua missão. Assim, para Ibarra (2010): “É há muito um dado adquirido que fazer negócios não é apenas uma questão de produção e de vendas. Atualmente, os stakeholders de uma empresa dão a conhecer as suas exigências, e têm o poder de responsabilizar a empresa pela satisfação das mesmas". As organizações devem tornar-se cada vez maios competitivas e continuar atentas às políticas, aos critérios e às normas que lhes são impostos pelo ambiente imediato e pelo mercado internacional, num mundo globalizado.

Hoje em dia, as organizações que procuram projeção a longo prazo sabem que necessitam de estar em constante mutação. Nesse sentido, a organização deve possuir 
uma estratégia inovadora e diferenciadora para se posicionar no tempo. Uma determinada empresa só poderá bater a sua concorrência se criar uma diferença que seja capaz de manter uma vantagem competitiva sustentável.

Assim, segundo Argenti et al. (2005), a comunicação estratégica é: "a comunicação ajustada à estratégia global de uma empresa, de modo a destacar e a reforçar o seu posicionamento estratégico". Assim, o posicionamento estratégico é definido complementarmente ao posicionamento estratégico da empresa. Este último situa a empresa, conforme perspetivado por diversos stakeholders, num lugar determinado do seu ambiente empresarial específico face aos seus concorrentes. É, em primeiro lugar, necessário delimitar este posicionamento analítico de modo a determinar, seguidamente, o posicionamento estratégico da empresa, isto é, a situação na qual gostaria de estar relativamente às perceções mentais dos seus stakeholders, e com base na qual define as estratégias a seguir e os objetivos a alcançar.

Para o efeito, a empresa também deve estar constantemente dependente do seu ambiente, tais como os requisitos de internacionalização ou os planos internos e os programas nacionais em termos de produtividade, cooperação e relações internacionais. Deve estar dependente do contexto político, cultural e social, do comportamento de outras organizações e do seu posicionamento no mercado, bem como da opinião pública em geral. Neste sentido, pode dizer-se que a comunicação estratégica não possui audiências ou público-alvo, mas antes stakeholders ligados à organização através dos seus próprios interesses específicos nos objetivos da empresa.

Ou seja, existe uma diferença, por exemplo, entre o público de uma campanha publicitária (o alvo da campanha publicitária ou do evento) e os grupos de stakeholders da organização. O conceito de stakeholder pode ser facilmente interpretado de forma errada como as pessoas a quem se dirigem as mensagens ou que foram meramente atingidas por essas mensagens. Os stakeholders, pelo contrário, são grupos que partilham algum significado com a organização, estendendo-se para além do público de clientes e consumidores da organização (embora, naturalmente, estes sejam, eles próprios, grupos de stakeholders).

Os stakeholders mantêm uma relação interativa com a organização (Argenti et al., 2005), podendo entrar em contacto com ela através de diferentes meios e canais e, se assim pretenderem, a qualquer momento, e não apenas através da aquisição de determinado produto. Do mesmo modo, os stakeholders também podem recusar participar ativamente, se assim o entenderem. Além disso, diferentes grupos de stakeholders poderão ligar-se entre si e criar sinergias com capacidade para influenciar a organização positiva ou negativamente. É, assim, possível que os stakeholders optem por participar ou não nas mensagens transmitidas pela organização com base no volume de esforço que querem ou estão dispostos a fazer.

A organização deve estar consciente de que não existem públicos cativos nem meros públicos-alvo, pelo contrário; cada caso deve ser estudado com base no seu próprio mérito, sendo necessário quantificar o nível de participação exigido a cada grupo e estimar a possibilidade real de o conquistar. Os objetivos poderão, então, ser definidos 
em conformidade, tendo em consideração o facto de os stakeholders estarem mais ou menos envolvidos no ambiente interno da organização a partir do qual será iniciado o processo de comunicação estratégica.

Finalmente, tendo em consideração todos os conceitos e ideias descritos acima, podemos propor a seguinte definição de comunicação estratégica nas organizações: "O esforço de gestão da comunicação a longo prazo exigido a uma organização, no seu ambiente específico, para que a sua relação com os seus stakeholders aproveite a sua evolução, no sentido de atingir os objetivos estabelecidos com base na perspetiva e na visão da sua estratégia global. Será operacionalizado um mecanismo de ações táticas que se dividirão, elas próprias, em planos de ação de comunicação com um prazo claramente definido, de modo a alcançar os objetivos definidos a priori".

Esta definição inclui, assim, as perspetivas da organização, da participação do sujeito, da gestão e o alcance dos objetivos a longo prazo, para além das táticas parciais necessárias para alcançar estes objetivos, e os planos de ação a curto prazo nos quais se divide o cumprimento desses objetivos.

A comunicação estratégica destina-se, então, a diferenciar a organização: o objetivo básico da gestão dos recursos intangíveis de uma empresa. Poderá, por conseguinte, dizer-se que está ao serviço deste aspeto da gestão. De facto, já é um facto aceite que a comunicação constitui a melhor ferramenta para gerir recursos intangíveis (Villafañe, 2005). O que é necessário compreender é que a própria comunicação "estratégica" é a melhor forma, em geral, de gerir esses recursos.

Para isso, será necessário que as organizações pensem de modo diferente e que tenham o apoio de uma estrutura de comunicação forte e eficaz. É necessário compreender a comunicação como o canal fundamental das organizações que as ligam ao ambiente. Uma gestão adequada da comunicação permitirá à organização conceber, desenvolver, pôr em prática e manter a sua estratégia nos diferentes níveis das suas ações, o que irá ajudar a ajustar as suas estratégias corporativas ao ambiente, garantindo a sua consistência e continuidade, e desenvolvendo uma linha de ação permanente. $O$ resultado será a projeção de uma imagem positiva junto dos stakeholders a curto prazo e uma melhoria da sua reputação a longo prazo, sendo este o objetivo último da gestão de recursos intangíveis.

\section{Conclusões}

Em primeiro lugar, podemos concluir que existe uma dificuldade considerável em definir comunicação estratégica devido à inconsistência polissémica das suas palavras que compõem o termo - "comunicação" e "estratégica" - o que levou diversos autores a fazer uma utilização abusiva do termo, nem sempre no sentido correto. $O$ interesse crescente na comunicação estratégica ao longo dos últimos anos foi reforçado pela prática profissional da comunicação nas organizações, o que ocorreu mais no sentido da integração com a estratégia global da empresa, sob supervisão direta da gestão sénior (Mattelart, 2000), do que sob os auspícios de departamentos como o departamento de marketing ou em forma de modos de comunicação parciais, como a publicidade. 
Em segundo lugar, a revisão do conceito de estratégia no contexto da comunicação nas organizações mostrou que a definição de comunicação estratégica deveria destacar determinados aspetos que ainda não tinham sido devidamente considerados:

- A comunicação estratégica tem que ser comunicação gerida. Em particular, nem toda a comunicação é comunicação estratégica, mas toda a comunicação estratégica é comunicação gerida.

- A comunicação estratégica e as estratégias de comunicação são duas coisas diferentes. A "comunicação estratégica" tem que pôr todas as formas de comunicação que se encontram à disposição da organização ao serviço dos seus objetivos, com um resultado que é mais do que a soma das "estratégias de comunicação" parciais.

- A empresa tem que estabelecer uma relação interativa com todos os seus stakeholders, e não só com as suas audiências ou públicos-alvo parciais. Os seus stakeholders mantêm uma relação com a organização que lhes permite estar em contacto com ela, se assim o entenderem, através dos vários canais e meios. O ideal é começar a gerir esta relação com os stakeholders internos da empresa e passar depois para os externos. Este processo irá ajudar a criar uma base sólida para a estratégia a seguir para alcançar determinados objetivos a longo prazo.

O conceito de comunicação estratégica possui claramente um lugar no contexto da comunicação, nas organizações em geral. Mais especificamente, a comunicação estratégica ganha em importância no contexto do modelo de comunicação em espiral discutido em Carrillo \& Tato (2005). O que é particularmente digno de nota nesse modelo é que a comunicação estratégica deve ser planeada a longo prazo. A comunicação estratégica encontra-se, realmente, mais próxima das políticas de gestão da organização do que da própria comunicação. As suas bases estão no cerne da organização, que, na presente abordagem organizacional, corresponderia à Gestão de Comunicação e Imagem. Acima de tudo, a comunicação estratégica não pode ser desenvolvida fora da organização, mas nem toda a comunicação realizada dentro da organização pode ser designada comunicação estratégica.

\section{REFERÊNCIAS}

Argenti, PA., Howell, RA. \& Beck, KA. (2005) "The strategic communication imperative", MIT Sloan Management Review, 46, 3: 82-90.

Carrillo, MV., García, M., Tato, JL. \& Castillo, A. (2013) Los retos de la comunicación. México: Pearson.

Carrillo, MV. \& Tato, JL. (2005) "El diseño de la "Comunicación Espiral” al servicio de las organizaciones del siglo XXI", Global Media Journal in Spanish, 2, 4.

Garrido, FJ. (2004) Comunicación estratégica. Las claves de la comunicación empresarial en el siglo XXI, Barcelona: Gestión 2000.

Hallahan, K., Holtzhausen, D., Van Ruler, B., Ver i , D. \& Sriramesh, K. (2007) “Defining Strategic Communication", International Journal of Strategic Communication, 1, 1: pp. 3-35.

Ibarra, W. (2010) Comunicación estratégica. Dispnível em http://www.comunicacionestrategica.pe/2008/02/ que-hace-un-comunicador-estrategico.html. 
Islas, O. (2005) “De las relaciones públicas a la comunicación estratégica”. Chasqui, disponível em http:// chasqui.comunica.org/content/view/44/56/.

Mattelart, A. (2000) La publicidad, Barcelona: Paidós.

Pérez, RA. (2001) Estrategias de Comunicación, Madrid: Ariel.

Pérez, RA. (2012) “Comunicación estratégica: sí claro. Pero, ¿qué implica "estratégica"?”, Revista Académica de Comunicación y Ciencias Sociales. 0, 2, Feb-Aug.

Pérez, RA. \& Massoni, S. (2009) Hacia una teoría general de la estrategia: Cambio de paradigma en el comportamiento humano, la sociedad y las instituciones, Madrid: Ariel.

Scheinsohn, D. \& Saroka, RH. (2000) La huella digital, Argentina: Fundación OSDE.

Schultz, DE., Tannenbaum, SI. \& Lauterborn, RF. (1994) The new marketing paradigm. Integrated marketing communications, Chicago: NTC Business Books.

Tironi, E. \& Carvallo, A. (2011).Comunicación estratégica, Chile: Taurus.

Villafañe (2005) La buena reputación, Madrid: Pirámide.

Este trabalho foi desenvolvido com o apoio do Governo da Extremadura e cofinanciado por Fundos Feder da União Europeia (UE).

头光穴

Recebido a 31-07-2014

Aceite a 06-10-2014 